\title{
WYZNACZENIE ZALEŻNOŚCI MIĘDZY EFEKTYWNOŚCIĄ DZIAŁANIA A SPRAWNOŚCIĄ MECHANICZNĄ MECHANIZMU RÓŻNICOWEGO
}

\begin{abstract}
Pojazdy samochodowe o napędzie na wszystkie koła ze stałym lub chwilowym podziałem momentu obrotowego charakteryzują się lepszą zdolnością do poruszania się w trudnym terenie czy też w różnorodnych warunkach drogowych z powodu podziału siły napędowej na przednią i tylną oś napędową. Polepszenie właściwości trakcyjnych pojazdów samochodowych od lat jest przedmiotem badań i rozważań w branży motoryzacyjnej, nie tylko z uwagi na większe możliwości samochodów, ale przede wszystkim z powodu zwiększenia bezpieczeństwa. Moment obrotowy przeniesiony przez mechanizm różnicowy na oś napędową, której koła znajdą się na nawierzchni o mniejszym współczynniku przyczepności, może być przyczyną utraty kontroli nad pojazdem. Szczególnie przy dużych prędkościach.

Przedmiotem pracy są badania wpływu sprawności centralnego mechanizmu różnicowego na dystrybucję momentu obrotowego poszczególnych osi napędowych. Badania przeprowadzone zostały na międzyosiowym mechanizmie różnicowym stosowanym w skrzynce rozdzielczej 6-cio biegowej manualnej skrzyni biegów.

Na podstawie dokonanej analizy wyników badań przedstawiono wpływ wielkości luzu pomiędzy czopem satelitów a średnicą otworów pod czopy satelitów w obudowie mechanizmu na wartość wyjściowego momentu obrotowego z mechanizmu różnicowego, a tym samym na jego sprawność oraz wykazano brak jednoznacznej, liniowej zależności pomiędzy sprawnością mechaniczną, a wartością wskaźnika dystrybucji momentu obrotowego.
\end{abstract}

Słowa kluczowe: Mechanizm różnicowy, moment obrotowy, dystrybucja momentu obrotowego, sprawność działania

\section{Wstęp}

Pojazdy samochodowe z napędem na wszystkie koła w porównaniu do pojazdów napędzanych na jedną oś charakteryzują się między innymi większym poziomem bezpieczeństwa oraz komfortem jazdy podczas różnorodnych warunków pogodowych oraz eksploatacyjnych, takich jak: śnieg, gołoledź czy nieutwardzone drogi. Rozdzielenie siły napędowej na wszystkie cztery koła w samo-

\footnotetext{
${ }^{1}$ Autor do korespondencji / corresponding author: Lucjan Król, Politechnika Opolska, Wydział Mechaniczny, ul. St. Mikołajczyka 5, 45-001 Opole, lucjan.krol@doktorant.po.edu.pl
} 
chodach osobowych oraz pochodnych (vany, pojazdy terenowe, SUV) pozwoliło na zwiększenie, w stosunku do pojazdów z napędem na przednią (FWD) lub tylną (RWD) oś, właściwości trakcyjnych i eksploatacyjnych takich jak [1,2]:

- większa zdolność rozpędzania, zwłaszcza na nawierzchniach o mniejszym współczynniku przyczepności,

- większa zdolność pokonywania wzniesień,

- większa przewidywalność zachowania pojazdu we wszystkich warunkach drogowych,

- większa elastyczność również przy niskiej prędkości obrotowej,

- mniejsza wrażliwość na działanie bocznego wiatru,

- neutralna charakterystyka auta w trakcie pokonywania zakrętów,

- korzystniejszy rozkład nacisków osi,

- przydatność do holowania przyczep o większej masie,

- równomierne zużycie opon.

Poprawa właściwości trakcyjnych pojazdów z napędem na wszystkie osie (AWD) jest możliwa głównie dzięki zwiększeniu siły napędowej, niestety związane jest to $\mathrm{z}$ bardziej skomplikowaną budową układu przeniesienia napędu. Mianowicie istnieje konieczność zastosowania dodatkowych zespołów w układzie przeniesienia napędu, najczęściej wyróżniających się innym sposobem sterowania lub konstrukcją oraz pozwalających na podział napędu w różnych proporcjach na poszczególne osie. Najczęściej spotykane dodatkowe zespoły układu AWD [1,3]:

- skrzynia rozdzielcza jako dodatkowa przekładnia zębata lub łańcuchowa do przekazania napędu na drugą oś napędową,

- międzyosiowy mechanizm,

- sprzęgło hydrokinetyczne,

- sprzęgło wiskotyczne (lepkościowe),

- sprzęgło Haldex,

- sprzęgło wielopłytkowe.

Niewątpliwie niezwykle istotnym elementem układu przeniesienia napędu na przednią i tylną oś jest międzyosiowy mechanizm różnicowy. Jego zadaniem jest zmniejszenie wartości naprężeń w układzie napędowym poprzez umożliwienie obracania się osi napędowych z różną prędkością obrotową podczas poruszania się pojazdu po torze krzywoliniowym bądź też z niejednakowymi promieniami dynamicznymi przednich oraz tylnych kół.

Polepszenie właściwości trakcyjnych pojazdów samochodowych od lat jest przedmiotem badań i rozważań w branży motoryzacyjnej, nie tylko z uwagi na większe możliwości samochodów, ale przede wszystkim z powodu zwiększenia bezpieczeństwa. Moment obrotowy przeniesiony przez mechanizm różnicowy na oś napędową, której koła znajdą się na nawierzchni o mniejszym współczynniku przyczepności, może być przyczyną utraty kontroli nad pojazdem. Szczególnie przy dużych prędkościach, co może być katastrofalne w skutkach. Dlatego też 
badania dotyczące sprawności oraz efektywności mechanizmów różnicowych są ważnym zagadnieniem, niejednokrotnie poruszanym w środowisku naukowym, m.in. w pracy [4], gdzie autorzy przedstawili przegląd zagadnień projektowania, rozwoju oraz testowania jednego z rodzajów mechanizmów różnicowych.

\section{Przedmiot badań}

Przedmiotem badań jest międzyosiowy mechanizm różnicowy (rys. 1.) stosowany w skrzynce rozdzielczej 6-cio biegowej manualnej skrzyni biegów, stosowanej między innymi w samochodach marki Audi. Nominalny podział momentu obrotowego przód:tył w badanym mechanizmie wynosi kolejno 40\%:60\% oraz charakteryzuje się współczynnikiem TDR od 2,9:1 do 3,5:1 dla tylnej osi oraz 1,55:1 do 1,9:1 dla przedniej.

a)

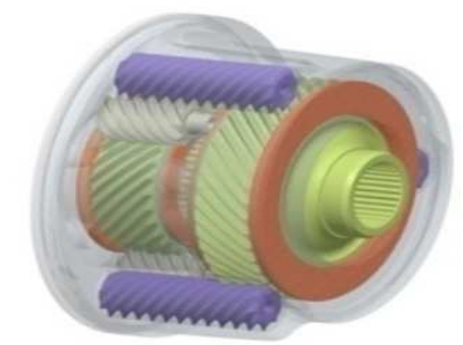

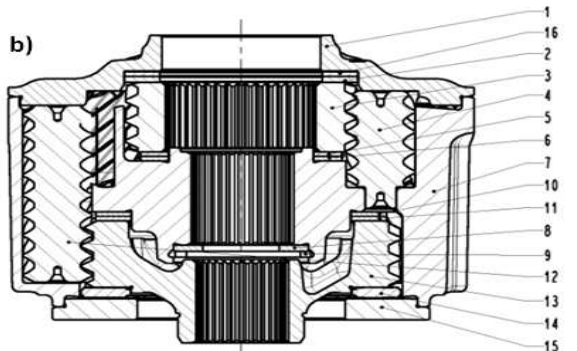

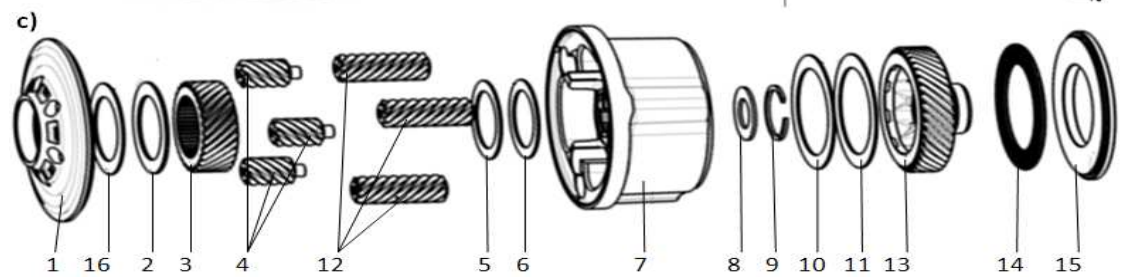

Rys. 1. Testowany centralny mechanizm różnicowy, gdzie: 1-żeliwna pokrywa obudowy; 2,5,6,10,11, 14,16-tarcze cierne; 3-koło koronowe przedniej osi; 4-komplet satelitów prawych (RH); 12-komplet satelitów lewych (LH); 7-jarzmo satelitów (obudowa) z wielowypustem; 8-podkładka oporowa; 9-pierścień osadczy; 13-koło koronowe tylnej osi; 15-stalowa pokrywa obudowy

Fig. 1. Tested central differential, 1-case cap; 2,5,6,10,11,14,16-washers; 3-LH side gear; 4-RH pinion gears; 12-LH pinion gears; 7-case body; 8-center washer; 9-snap ring; 13-RH side gear; 15-steel cap

Cechą określającą efektywność działania badanego mechanizmu różnicowego jest współczynnik TDR (Torque Distibution Ratio), który definiuje stosunek momentu obrotowego przekazywanego na oś napędową o lepszej przyczepności w stosunku do drugiej osi dla różnicy prędkości $\Delta \mathrm{n} \neq 0[1,7]$ tj.

$$
\mathrm{TDR}=\frac{\mathrm{M}_{2}}{\mathrm{M}_{1}}
$$

gdzie:

dla $M_{2}>M_{1}, M_{1} \neq 0, \Delta n \neq 0$, 
$\mathrm{M}_{1}$ i $\mathrm{M}_{2}$ - moment obrotowy poszczególnych kół napędowych, $\Delta \mathrm{n}$ - różnica prędkości obrotowej kół napędowych.

Wartość współczynnika TDR 3:1 oznacza przekazanie trzykrotnie większego momentu obrotowego na koło napędowe o lepszej przyczepności, w stosunku do koła napędowego będącego w poślizgu.

Jako efektywność działania mechanizmu rozumieć należy stosunek podziału momentu obrotowego w granicach tolerancji właściwych dla poszczególnego trybu pracy. Pomiar współczynnika TDR przeprowadzono na testerze sprawdzającym ogólną charakterystykę pracy mechanizmu różnicowego w czterech trybach pracy, które przedstawione zostały w tabeli 1 . Poszczególne tryby pracy odpowiadają różnym sytuacjom drogowym takim jak rozpędzanie pojazdu lub hamowanie silnikiem w przypadku poślizgu jednej z osi napędowych.

Tabela 1. Równania wartości trybu pracy $1 \div 4$ oraz konfiguracja pomiarowa, gdzie: $\mathrm{M}_{\mathrm{P}}$ - moment obrotowy przedniej osi; $\mathrm{M}_{\mathrm{T}}$ - moment obrotowy tylnej osi; $\mathrm{n}_{\mathrm{P}}$ - prędkość obrotowa osi przedniej; $\mathrm{n}_{\mathrm{T}}$ - prędkość obrotowa osi tylnej, na podstawie [7]

Table 1 . Vehicle test mode equations $1 \div 4$ and measuring configuration, where: $M_{P}$ - front axle torque; $\mathrm{M}_{\mathrm{T}}$ - rear axle torque; $n_{P}$ - front axle rotating speed; $n_{T}-$ rear axle rotating speed

\begin{tabular}{|l|c|c|c|c|}
\hline \multicolumn{1}{|c|}{ TDR } & TDR 1 & TDR 2 & TDR 3 & TDR 4 \\
\hline Kondycja napędu & zwalnianie & napędzanie & zwalnianie & napędzanie \\
\hline $\begin{array}{l}\text { Kierunek działania } \\
\text { blokady }\end{array}$ & przód & przód & tył & tył \\
\hline $\begin{array}{l}\text { Dystrybucja mo- } \\
\text { mentu obrotowego }\end{array}$ & $M_{P}>M_{T}$ & $M_{P}>M_{T}$ & $M_{P}<M_{T}$ & $M_{P}<M_{T}$ \\
\hline $\begin{array}{l}\text { Rozkład prędkości } \\
\text { obrotowych osi }\end{array}$ & $n_{P}>n_{T}$ & $n_{P}<n_{T}$ & $n_{P}<n_{T}$ & $n_{P}>n_{T}$ \\
\hline Równanie TDR & $\frac{M_{P}}{M_{T}}$ & $\frac{M_{P}}{M_{T}}$ & $\frac{M_{T}}{M_{P}}$ & $\frac{M_{T}}{M_{P}}$ \\
\hline
\end{tabular}

Kolejną istotną cechą mechanizmu różnicowego jest jego sprawność mechaniczna. Ujmuje ona straty mocy w mechanizmie wynikające z tarcia, głównie [6]:

- w zazębieniu ze względu na tarcie współpracujących zębów,

- tarcie współpracujących powierzchni kół zębatych z obudową mechanizmu i tarczami ciernymi,

- w oleju z powodu jego mieszania przy smarowaniu zanurzeniowym.

Sprawność mechaniczna przekładni zębatej określa się jako stosunek mocy uzyskanej na wyjściu z przekładni do mocy włożonej na wejściu do przekładni $[6], \mathrm{tj} .:$ 


$$
\eta=\frac{P_{2}}{P_{1}}
$$

gdzie:

$\eta$ - sprawność mechaniczna,

$\mathrm{P}_{1}$ - moc włożona na wejściu do przekładni,

$\mathrm{P}_{2}-$ moc uzyskana na wyjściu z przekładni.

W przypadku badanego mechanizmu różnicowego sprawność mechaniczną określono poprzez stosunek momentu obrotowego uzyskanego na wyjściu $\mathrm{z}$ mechanizmu do momentu obrotowego dostarczonego na wejście do mechani$\mathrm{zmu}, \mathrm{tj}$.

$$
\eta=\frac{M_{1}}{M_{0}}
$$

gdzie:

$\mathrm{M}_{1}$ - moment obrotowy uzyskany na wyjściu z mechanizmu,

$\mathrm{M}_{0}$ - moment obrotowy dostarczony do mechanizmu.

Biorąc pod uwagę fakt iż centralny mechanizm różnicowy rozdziela moment obrotowy na przednią i tylną oś,

$$
M_{1}=M_{P}+M_{T}
$$

to sprawność badanego mechanizmu różnicowego (równanie 3) można przedstawić w następujący sposób.

$$
\eta=\frac{M_{P}+M_{T}}{M_{0}}
$$

gdzie:

$\mathrm{M}_{\mathrm{P}}-$ moment obrotowy uzyskany na przedniej osi,

$\mathrm{M}_{\mathrm{T}}-$ moment obrotowy uzyskany na tylnej osi.

\section{Metodyka oraz wyniki badań}

Badania zostały przeprowadzone na próbce liczącej 6 sztuk mechanizmów różnicowych wyselekcjonowanych $\mathrm{z}$ bieżącej produkcji. Określone kryteria selekcji zakładały odseparowanie dwóch grup mechanizmów po 3 sztuki. Pierwszą grupę stanowiły mechanizmy z wartościami współczynników TDR poniżej dolnej granicy specyfikacji (mechanizmy NOK). Grupa druga mechanizmów (mechanizmy OK) charakteryzowała się największymi wartościami współczynników TDR (tabela 2). Następnie wszystkie mechanizmy różnicowe zostały rozmontowane w celu analizy zużycia powierzchni roboczych oraz dokonania pomiarów cech geometrycznych części składowych w laboratorium metrologicznym. 
Przeprowadzając analizę części składowych mechanizmu zaobserwowano zużycie powierzchni na czopach wszystkich satelitów RH w mechanizmach grupy pierwszej (mechanizmy NOK), czego nie zaobserwowano w pozostałych mechanizmach. Wyniki pomiarów wskazały błędy walcowości czopów. Odkształcenia plastyczne czopów w postaci stożka bezpośrednio przyczyniały się do zmniejszenia wartości luzu pomiędzy czopami satelitów RH, a średnicą pod czopy satelitów RH w obudowie mechanizmu [7].

Tabela 2. Grupa badanych mechanizmów wraz z wartościami współczynników TDR, gdzie: kolor szary - wartości poniżej dolnej granicy tolerancji; pogrubiona kursywa - wartości na granicy dolnej tolerancji, pozostałe wartości TDR - wartości w tolerancji

Table 2. Group of analyzed differentials with TDR values, where: grey - values below LSL; bold italic - LSL value; green - in tolerance level

\begin{tabular}{|c|c|c|c|c|c|}
\hline $\mathrm{Nr}$ & TDR & $\begin{array}{l}\text { wartość TDR } \\
\text { sztuk NOK }\end{array}$ & $\mathrm{Nr}$ & TDR & $\begin{array}{c}\text { wartość TDR } \\
\text { sztuk OK }\end{array}$ \\
\hline \multirow{4}{*}{1} & 1 & 1,45 & \multirow{4}{*}{4} & 1 & 1,50 \\
\hline & 2 & 1,49 & & 2 & 1,60 \\
\hline & 3 & 2,63 & & 3 & 2,72 \\
\hline & 4 & 2,75 & & 4 & 3,03 \\
\hline \multirow{4}{*}{2} & 1 & 1,42 & \multirow{4}{*}{5} & 1 & 1,47 \\
\hline & 2 & 1,52 & & 2 & 1,60 \\
\hline & 3 & 2,63 & & 3 & 2,70 \\
\hline & 4 & 2,79 & & 4 & 3,00 \\
\hline \multirow{4}{*}{3} & 1 & 1,44 & \multirow{4}{*}{6} & 1 & 1,44 \\
\hline & 2 & 1,53 & & 2 & 1,60 \\
\hline & 3 & 2,64 & & 3 & 2,66 \\
\hline & 4 & 2,81 & & 4 & 3,00 \\
\hline
\end{tabular}

Przedstawione wartości współczynnika TDR zostały zarejestrowane podczas testów funkcjonalnych przeprowadzonych na maszynie typu End Of Line Tester (EOL Tester). Tego typu maszyny w branży motoryzacyjnej najczęściej wykorzystywane są do 100 procentowej kontroli wyprodukowanych części, tutaj mechanizmów różnicowych. Testy funkcjonalne na zastosowanej maszynie mogą odbywać się przy maksymalnym poziomie momentu obrotowego do $650 \mathrm{Nm}$. Dodatkowo maszyna ma możliwość pomiaru luzu międzyzębowego oraz analizy Noise Vibration and Harshness (NVH).

Na pomiary wartości momentu obrotowego, a następnie wyniki wskaźnika TDR może mieć wpływ:

- Ciśnienie oraz przepływ oleju, który jest doprowadzany do mechanizmu różnicowego podczas testowania,

- Temperatura oleju,

- Zanieczyszczenie oleju drobinkami fosforu pochodzącego z kół zębatych mechanizmu,

- Rodzaj oleju, 
- Zanieczyszczenia wewnątrz mechanizmu,

- Temperatura mechanizmu.

Celem zredukowania wpływu wyżej wymienionych czynników maszyna testująca wyposażona jest w szereg czujników nieustannie monitorujących warunki fizyczne podczas testów funkcjonalnych. Dodatkowo opracowane instrukcje i procedury określają standardowe oraz systematyczne postępowanie przy przeglądach i inspekcjach maszyny testującej. Ograniczenie czynników wpływających na wyniki testów oraz właściwe zaprojektowanie procesu wytwórczego mechanizmów różnicowych pozwoliło na uzyskanie oraz ciągłe utrzymywanie rzeczywistego rozrzutu wyników pomiarowych poniżej $1 \%$.

Dodatkowo do celów badawczych wykorzystano specjalnie wykonaną obudowę badanego mechanizmu, pozwalającej na weryfikację wpływu dowolnego komponentu przy zachowaniu minimalnej ilości zmiennych. Wielokrotny montaż oraz demontaż komponentów umożliwiło zastosowanie połączenia śrubowego pokrywek z korpusem. W celu wyeliminowania wpływu czynników zewnętrznych na wartości pomiarów współczynnika TDR lub ich losowego rozrzutu ustalono jednakowe warunki testu mechanizmu w wersji skręcanej, które były ściśle przestrzegane podczas kolejnych etapów.

Chcąc zweryfikować wpływ wielkości luzu pomiędzy czopami satelitów RH, a średnicą pod czopy satelitów RH w obudowie mechanizmu na sprawność mechaniczną oraz wskaźnik TDR, przygotowano zestaw pomierzonych wcześniej części składowych, oraz zmontowano je w skręcanej wersji obudowy. Po przeprowadzonych testach funkcjonalnych mechanizm był rozmontowywany w celu zwiększenia luzu, a następnie montowany z zachowaniem pełnej, wzajemnej orientacji części składowych w celu zminimalizowania zmiennych mogących zakłócić pomiary. Zwiększenie luzu odbywało się poprzez zmniejszenie średnicy czopa satelity RH metodą szlifowania. Uzyskane w ten sposób wartości momentu obrotowego oraz współczynnika TDR podano w tabeli 3.

Tabela 3. Wartości momentu obrotowego oraz wskaźnika dystrybucji momentu obrotowego Table 3. Torque and TDR factor values

\begin{tabular}{|c|c|c|c|c|c|c|c|c|c|c|c|c|}
\hline \multirow{3}{*}{$\begin{array}{l}\mathbf{T} \\
\mathbf{D} \\
\mathbf{R}\end{array}$} & \multicolumn{12}{|c|}{ Wielkość luzu, mm } \\
\hline & \multicolumn{2}{|c|}{0,143} & \multicolumn{2}{|c|}{$\mathbf{0 , 1 7 3}$} & \multicolumn{2}{|c|}{0,203} & \multicolumn{2}{|c|}{0,213} & \multicolumn{2}{|c|}{0,243} & \multicolumn{2}{|c|}{0,363} \\
\hline & TDR & $\begin{array}{c}M_{1} \\
\mathbf{N m} \\
\end{array}$ & TDR & $\begin{array}{c}\mathbf{M}_{\mathbf{1}} \\
\mathbf{N m} \\
\end{array}$ & TDR & $\begin{array}{c}\mathbf{M}_{1} \\
\mathbf{N m}\end{array}$ & TDR & $\begin{array}{c}\mathbf{M}_{\mathbf{1}} \\
\mathbf{N m}\end{array}$ & TDR & $\begin{array}{c}\mathbf{M}_{\mathbf{1}} \\
\mathbf{N m} \\
\end{array}$ & TDR & $\begin{array}{c}\mathbf{M}_{1} \\
\mathbf{N m}\end{array}$ \\
\hline 1 & 1,45 & 497,5 & 1,46 & 498,2 & 1,49 & 496,3 & 1,51 & 473,5 & 1,50 & 494,5 & 1,51 & 478,1 \\
\hline 2 & 1,60 & 475,9 & 1,61 & 476,7 & 1,63 & 475,2 & 1,63 & 459,6 & 1,63 & 480,8 & 1,63 & 454,5 \\
\hline 3 & 2,82 & 494,1 & 2,84 & 494,3 & 2,86 & 492,5 & 2,87 & 469,9 & 2,86 & 490,3 & 2,85 & 474,6 \\
\hline 4 & 2,95 & 473,1 & 3,01 & 473,8 & 3,04 & 472,2 & 3,08 & 455,9 & 3,07 & 477,8 & 3,09 & 450,9 \\
\hline
\end{tabular}




\section{Analiza wyników i wnioski}

Mechanizmy NOK charakteryzowały się wartościami luzu poniżej $0,150 \mathrm{~mm}$, natomiast najmniejsza wartość luzu mechanizmów OK wynosiła 0,166 mm (rys. 2). Mechanizmy, które spośród badanej próbki miały najwyższą wartość luzu, kolejno $0,206 \mathrm{~mm}$ i $0,208 \mathrm{~mm}$ charakteryzowały się najmniejszą sprawnością mechaniczną w badanej próbce w każdym trybie pracy. Można wnioskować iż wielkość luzu ma wpływ na wartość wskaźnika dystrybucji momentu obrotowego oraz sprawność mechaniczną badanych mechanizmów różnicowych.

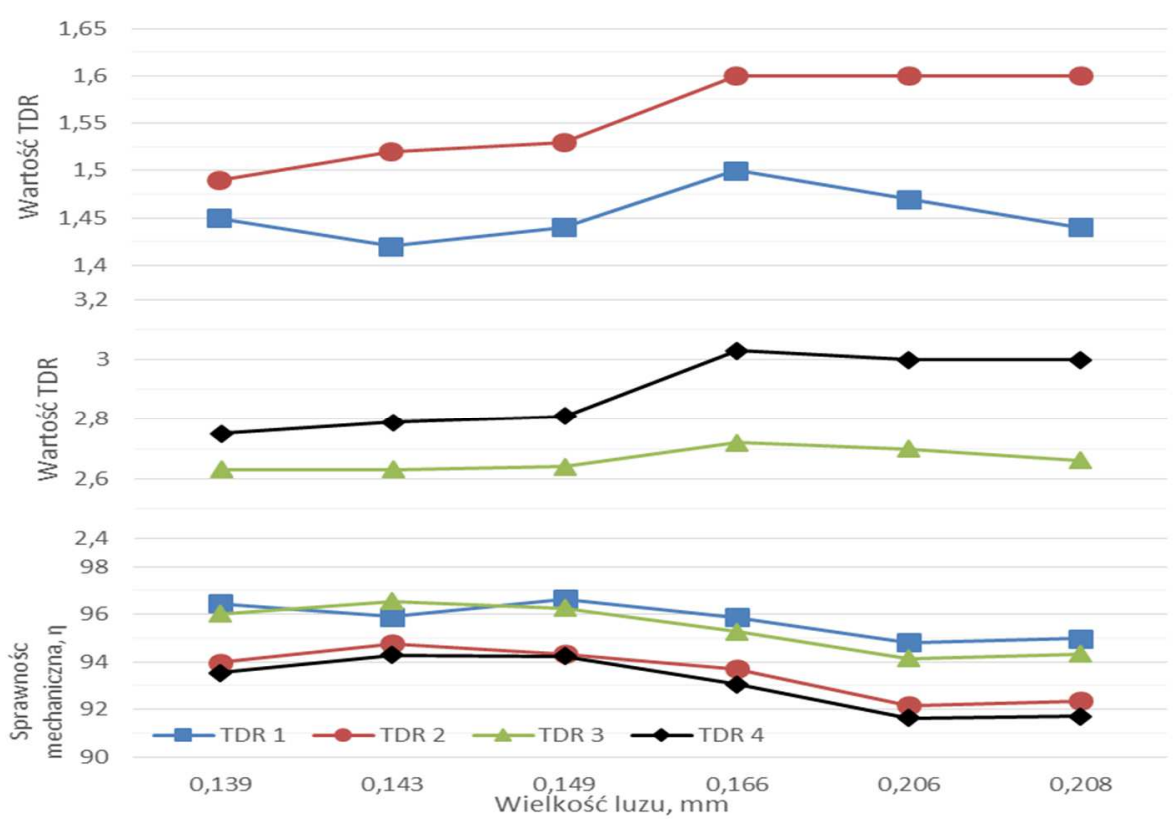

Rys. 2. Zależność między wskaźnikiem dystrybucji momentu obrotowego a sprawnością mechaniczną mechanizmu różnicowego w odniesieniu do wielkości luzu. Wartości dla mechanizmów z grupy OK i NOK

Fig. 2. Correlation between TDR factor and central differential mechanical efficiency in relation to the size of the clearance. Values for OK and NOK differentials

Na rysunku 3 przedstawiono wpływ zmiany wielkości luzu pomiędzy czopami satelitów RH, a średnicą pod czopy satelitów RH w obudowie mechanizmu na wartość wskaźnika dystrybucji momentu obrotowego oraz sprawność mechaniczną. Analizując wyniki testu można stwierdzić zwiększenie wartości współczynnika TDR wraz ze wzrostem wielkości luzu, co najbardziej jest widoczne dla trybu pracy mechanizmu TDR 1 oraz TDR 4 . We wszystkich trybach pracy sprawność mechaniczna dla próbek o wielkości luzu $0,213 \mathrm{~mm}$ i $0,363 \mathrm{~mm}$ jest znacząco niższa od pozostałych, natomiast dla próbek o wielkości luzu $0,143 \mathrm{~mm}$, 0,173 $\mathrm{mm}$ oraz $0,203 \mathrm{~mm}$ sprawność mechaniczna lokalnie, w obrębie każdego 
z trybu pracy jest zbliżona względem siebie. Przy wielkości luzu $0,363 \mathrm{~mm}$ dla TDR 1 i TDR 3 sprawność mechanizmu jest większa w stosunku do próbki o wielkości luzu $0,213 \mathrm{~mm}$, natomiast dla TDR 2 oraz TDR 4 sprawność mechanizmu jest większa dla wielkości luzu $0,213 \mathrm{~mm}$. Przy wielkości luzu 0,243 $\mathrm{mm}$ dla TDR 2 oraz TDR 4 sprawność mechanizmu jest największa pomimo wartości współczynnika TDR zbliżonej do próbek o wielkości luzu 0,213 mm i $0,263 \mathrm{~mm}$. Przy zmianie wielkości luzu od $0,203 \mathrm{~mm}$ do $0,363 \mathrm{~mm}$ wartość TDR 2 była równa 1,63, przy czym sprawność mechanizmu wahała się od 95\% do $90,1 \%$.

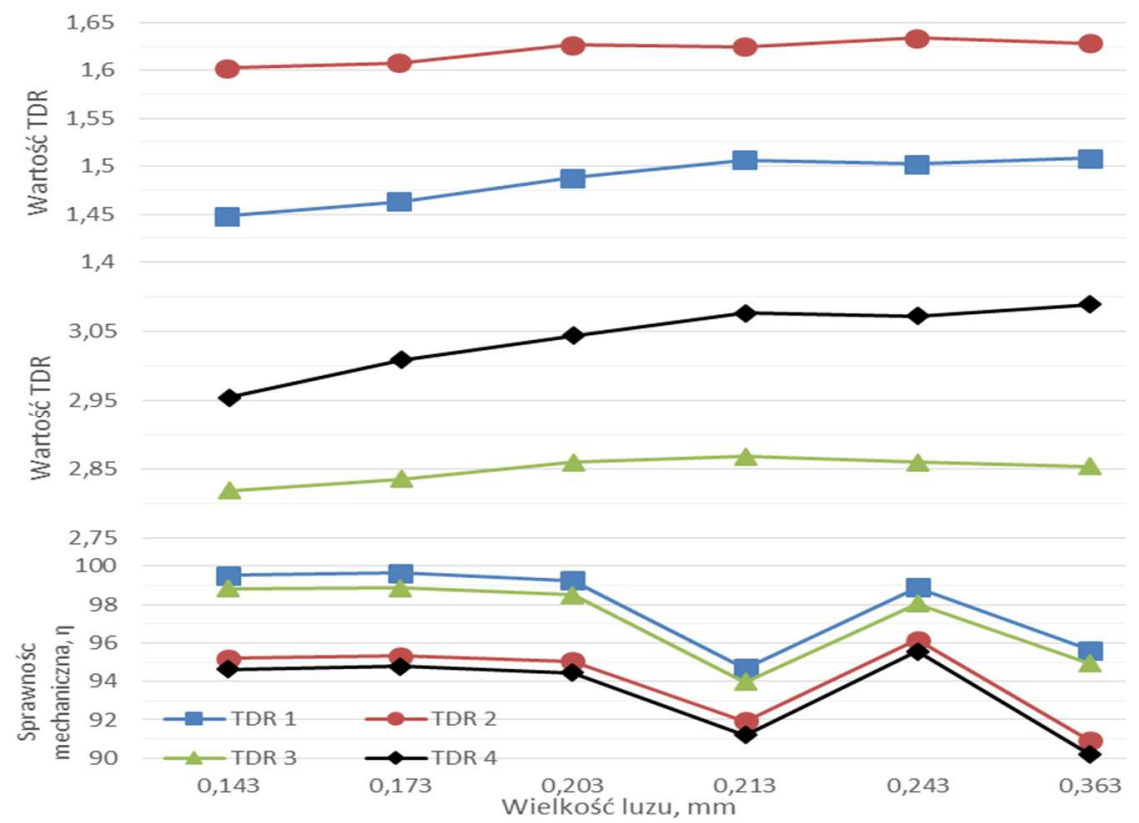

Rys. 3. Zależność między wskaźnikiem dystrybucji momentu obrotowego a sprawnością mechaniczną mechanizmu różnicowego w odniesieniu do wielkości luzu. Wartości dla mechanizmu w wersji skręcanej - test zmiany wartości luzu

Fig. 3. Correlation between TDR factor and central differential mechanical efficiency in relation to the size of the clearance. Values for Mode 3 bolted version of differential - changing the size of clearance was examined

Z przeprowadzonych badań oraz analizy otrzymanych wyników można sformułować następujące wnioski:

1. Wzrost wielkości luzu pomiędzy czopem satelitów RH a ich gniazdem w korpusie ma wpływ na wzrost wartości wszystkich trybów pracy współczynnika TDR;

2. Nie stwierdzono jednoznacznego, liniowego wpływu wielkości luzu pomiędzy czopami satelitów RH, a średnicą pod czopy satelitów RH w obudowie mechanizmu na poprawę sprawności mechanicznej badanego mechanizmu 
różnicowego. Dopuszcza się możliwość występowania nieliniowej zależności pomiędzy wielkością luzu, a sprawnością mechaniczną, indywidualnie dla każdego z trybu pracy. Należy przeprowadzić kolejne testy w zakresie wielkości luzu od 0,213 mm do 0,363 mm.

3. Brak jednoznacznej, liniowej zależności pomiędzy sprawnością mechaniczną, a wartością wskaźnika dystrybucji momentu obrotowego.

\section{Literatura}

[1] Król L., Badania nad zwiększeniem efektywności działania centralnego mechanizmu różnicowego samochodu osobowego. Praca dyplomowa magisterska, Wydział Mechaniczny, Politechnika Wrocławska, Wrocław 2014, s. 85.

[2] Gabryelewicz M., Podwozia i nadwozia pojazdów samochodowych 1 Podstawy teorii ruchu i eksploatacji oraz układ przeniesienia napędu. WKŁ, Warszawa, 2012.

[3] Jackowski J., Łęgiewicz J., Wieczorek M., Pojazdy samochodowe. Samochody osobowe i pochodne. WKE, Warszawa, 2011.

[4] Fox, M. and Grogg, J., "Development of Front-Wheel-Drive ELSD for Efficient Performance and Safety," SAE Technical Paper 2012-01-0305, 2012.

[5] Wyniki badań, rysunki oraz zdjęcia American Axle and Manufacturing, rok 2012.

[6] Dziama A., Michniewicz M., Niedźwiedzki A., Przekładnie zębate. PWN, Warszawa 1995.

[7] Król L. Sposób poprawienia efektywności działania mechanizmu różnicowego QP1 w urządzeniu transportowym, Logistyka 4/2015 s.9272-9277, ISSN 1231-5478.

\section{DETERMINATION OF THE RELATION BETWEEN PERFORMANCE EFFICIENCY AND MECHANICAL EFFICIENCY OF THE DIFFERENTIAL}

\section{S u m m a r y}

All-wheel-drive vehicles with a constant or momentary torque distribution have a better ability to drive in difficult ground or in a variety of road conditions due to distribute torque on the front and rear drive axles. Improving the traction properties of motor vehicles has been a subject of research and consideration in the automotive industry for years, not only because of the greater possibilities of vehicles, but primarily because of increased safety. The torque distributed by the differential to the drive axle, whose wheels are on a surface with a lower adhesion, can cause loss of control of the vehicle. Especially at high speeds.

The subject of the research work is the mechanical efficiency effect of the center differential to distribute torque of each axis drive. The research were conducted on an center differential used in a six-speed manual gear box. Based on the analysis of the test results shows the influence of the clearance size between the RH pinions pilots and their pocket in case body to the out-put torque from the differential and thus its mechanical efficiency. Test result analysis shows also the lack of clear, linear correlation between the mechanical efficiency and the value of the torque distribution ratio.

Keywords: differential, torque, torque distribution, mechanical efficiency

Przestano do redakcji: 24.02 .2017 r.

Przyjęto do druku: 28.04.2017 r. 